\title{
ESTEREÓTIPOS DA MULHER NO DISCURSO DE AUTOAJUDA
}

\author{
(Women's stereotypes in self-help discourse)
}

\author{
Anna Flora Brunelli ${ }^{1}$ \\ (UNESP/FEsTA)
}

\begin{abstract}
Building on the foundations of French Discourse Analysis and Social Psychology's developments on the issue of stereotypes, this paper analyzes the images of women available in works of self-help for women. With this purpose in mind, we have especially taken into account aphorizing enunciations present in works of this kind currently circulating in the market. The analysis shows the contradiction inherent to the self-help discourse for women, which proposes to women a pattern of behavior consistent with their emancipation, but, at the same time, contributes to keeping certain female stereotypes associated with their traditional roles.
\end{abstract}

Keywords: stereotype, self-help discourse, women, aphorisation.

\section{RESUMO}

Nesse trabalho, a partir dos fundamentos da Análise do Discurso de linha francesa e das reflexões que a Psicologia Social desenvolve sobre a questão dos estereótipos, analisam-se as imagens de mulher presentes em obras de autoajuda destinadas a mulheres. Para tanto, consideram-se, especialmente, enunciados aforizados presentes em obras do gênero que estão circulando atualmente no mercado. A análise revela a contradição própria do discurso de autoajuda para mulheres, que propõe à mulher um padrão de comportamento mais condizente com a sua emancipação ao

1. Mestre e Doutora em Linguística pelo Instituto de Estudos da Linguagem (IEL) da UNICAMP. Desde 1997, é professora do Departamento de Estudos Linguísticos e Literários (DELL) do Instituto de Biociências, Letras e Ciências Exatas (IBILCE) - UNESP/Campus de São José do Rio Preto (SP). É membro do Centro de Pesquisa FEsTA (Fórmulas e Estereótipos: Teoria e Análise) - IEL/ UNICAMP. 
mesmo tempo em que colabora com a manutenção de certos estereótipos femininos associados a seus papéis tradicionais.

Palavras-chave: estereótipos, discurso de autoajuda, mulheres, aforização.

\section{Introdução}

Neste trabalho, adotando o ponto de vista da Análise do Discurso de linha francesa, analisamos alguns aspectos do discurso de autoajuda destinado a mulheres. Mais exatamente, procuramos identificar as imagens de mulher presentes nesse discurso, a fim de verificarmos se esse discurso colabora ou não com a manutenção de certos estereótipos femininos que desvalorizam a mulher socialmente.

Nosso corpus é constituído por algumas obras do gênero que estão atualmente circulando no mercado, tais como: "Por que os homens amam as mulheres poderosas" (Argov, 2009), "Por que os homens se casam com as manipuladoras" (Argov, 2010), "O que toda mulher inteligente deve saber" (Carter e Sokol, 2006), "Homens gostam de mulheres que gostam de si mesmas" (Carter e Sokol, 2008), "Mulheres ousadas chegam mais longe" (Frankel, 2005), "Mulheres boazinhas não enriquecem" (Frankel, 2006), "Abaixo a mulher capacho" (Abrão, 2009), "Mulher em primeiro lugar" (Sansone, 2008). O discurso de autoajuda, de modo geral, destina-se a ensinar fórmulas para que os seus leitores alcancem o sucesso financeiro e profissional. No caso das obras em questão, trata-se de ensinar essas fórmulas às mulheres, e/ou de lhes ensinar as fórmulas para que sejam felizes em seus relacionamentos. Assim, pela temática, o discurso de autoajuda parece representar a mulher de uma forma diversificada, segundo a qual a ela tem, ao lado dos interesses que tradicionalmente lhe são associados, tais como relacionamentos/casamento e família, também outros interesses como a carreira e a ascensão financeira, o que seria mais condizente como a imagem da mulher moderna.

Na verdade, qualquer que seja o tema, os livros de autoajuda se constroem a partir de duas imagens de mulheres: uma que é a imagem positiva e que corresponde ao comportamento que os livros pretendem 
ensinar às suas leitoras e outra que é a imagem que os livros rejeitam e que associam a maioria das mulheres, entre as quais incluem as suas leitoras. Desse modo, de um lado, temos a mulher confiante e segura de si, que é bem sucedida em todos os seus intentos, sejam os profissionais e financeiros, sejam os pessoais. Para se referir a esse tipo de mulher, o discurso de autoajuda emprega expressões como: "mulher ousada" (Frankel, 2005), "mulher inteligente" (Carter e Sokol, 2006 e 2008), "mulher manipuladora" (Argov, 2010), "mulher poderosa" (Argov, 2009). Por outro lado, temos a mulher insegura, que desconhece o seu potencial e o modo correto de usá-lo, a qual o discurso de autoajuda se refere por meio de expressões como "mulher boazinha" (Frankel, 2005 e 2006, Argov, 2009), "mulher capacho" (Abrão, 2009 e Argov, 2009), "boa moça" (Argov, 2010). Muitas vezes, essa mulher insegura é retratada como uma pessoa que não tem controle emocional e que se deixa levar pelas emoções. A esse respeito, vejamos alguns trechos de obras do corpus:

(01) A mulher inteligente é aquela que conhece com toda a clareza e segurança seu valor e seu poder. (...) sabe como enfrentar e superar desafios, e como cuidar da relação em períodos de calmaria. Ou seja, a mulher inteligente sabe quem ela é, se respeita e se faz respeitar. Ela gosta de si mesma, é capaz de se controlar e de controlar sua vida. É claro que a mulher inteligente, como qualquer ser humano normal, tem seus momentos de fraqueza e de insegurança. É claro que ela tem seus medos e hesitações. A mulher inteligente erra muitas vezes. A grande diferença é que ela tem consciência disso, aceita seus limites e se esforça para superálos. Talvez fosse confortador descobrir que, quando ninguém está olhando, as mulheres inteligentes se entopem de chocolates e sorvetes, choram desconsoladamente e se comunicam dia e noite com seus terapeutas. Mas elas não fazem essas coisas. É possível que isso deixe você muito irritada e cheia de inveja.

(Carter e Sokol, 2008: 7; grifo nosso)

(02) Nos capítulos que você está prestes a ler, aprenderá a modificar sua abordagem. Você vai compreender por que ele tem de ficar se 
perguntando por que você não age como se estivesse desesperada para se casar como todas as mulheres que conhece. Quando você parecer diferente, no sentido de que não parte para cima dos homens com um plano pronto para chegar ao casamento, então receberá mais propostas do que é capaz de assimilar

(Argov, 2010:17)

Nessas passagens, percebemos claramente os dois tipos de mulheres a que o discurso de autoajuda se refere: a mulher inteligente, segura de si e capaz de se controlar, e a outra mulher, aquela com a qual o discurso de autoajuda associa as suas leitoras: a mulher insegura e descontrolada (que se entope de chocolate e sorvetes, que chora desconsoladamente, que se comunica dia e noite com o terapeuta, que, diante do sucesso das outras, sente irritação e inveja, que está desesperada para casar, etc.).

Considerando essa suposta deficiência associada às mulheres, isto é, que elas não têm auto-estima e/ou controle emocional, os livros de autoajuda se apresentam como uma forma de sanar essa deficiência, para que a mulher consiga efetivamente concretizar os seus desejos. Assim, como se trata de obras que ensinam às mulheres o que elas devem fazer para serem bem sucedidas nas tarefas e nos projetos em que se envolvem, as obras de autoajuda para mulheres podem ser lidas como o indício de que as mulheres são mesmo pessoas carentes de orientação, como se elas realmente precisassem que alguém lhes dissesse exatamente o que fazer para evitar que continuem cometendo os velhos erros que culminam no fracasso desses projetos. De fato, o discurso de autoajuda dirigido a mulheres precisa se apoiar nessa imagem feminina negativa, do contrário ele não se justifica, já que se trata de um discurso cujo objetivo é orientar o seu destinatário. Ou seja, para se legitimar como um discurso cuja finalidade é ditar padrões de comportamento, o discurso de autoajuda pressupõe, do ponto de vista pragmático, que o seu destinatário seja carente dessa orientação, pressuposto sem o qual o discurso não tem razão de ser. Desse ponto de vista, parece-nos possível dizer que o discurso de autoajuda dirigido às mulheres, ao se apoiar numa imagem feminina negativa para se constituir, colabora com a desvalorização social da 
mulher. Assim, mesmo que ele se apresente com o intuito de ajudálas, transmitindo-lhes informações que supostamente poderiam transformar o seu modo "incorreto" de ser e de pensar, que é, segundo esse discurso, o responsável pelos seus fracassos, só o fato de ele o fazer com base numa imagem negativa da mulher já nos parece o suficiente para reforçá-la, especialmente porque essa imagem negativa é tomada como ponto de partida desse discurso, isto é, como se ela fosse de fato um retrato fidedigno das mulheres.

\section{Aforizações e estereótipos}

No discurso de autoajuda, encontramos uma imagem negativa da mulher até mesmo em enunciados aforizados. Maingueneau (2010) emprega essa designação para se referir a enunciados cujo significante e significado são considerados no interior de uma enunciação pregnante (pela prosódia, pelas rimas, pelas metáforas, etc.), que facilita sua memorização e, consequentemente, sua circulação. Mais exatamente, esses enunciados desfrutam de um status pragmático especial, isto é, eles decorrem de um regime de enunciação específico, que o autor chama de enunciação aforizante, em oposição à enunciação textualizante. Vejamos as suas principais diferenças entre essas duas ordens enunciativas:

a) na enunciação textualizante, há posições correlativas de produção e de recepção, que são especificadas pelas restrições da cena relativa ao gênero a que o texto pertence. Trata-se de papéis pertinentes para a cena verbal, na qual a responsabilidade do dizer é partilhada e negociada. $\mathrm{Na}$ enunciação aforizante, em contrapartida, no lugar de posições correlativas, há uma instância que fala a uma espécie de auditório universal, que não se reduz a um destinatário específico; não há, então, protagonistas colocados no mesmo plano, pois a enunciação, de tipo monologal, centra-se no locutor, apreendido em sua totalidade, isto é, sem ruptura entre a instância discursiva e a instância tomada fora 
da enunciação. Nesse caso, é o próprio indivíduo que se exprime, além e aquém de qualquer papel discursivo;

b) na enunciação textualizante, os pensamentos estão articulados por meio de restrições de jogos de linguagem de diversas ordens (argumentar, narrar, responder, etc.); na aforizante, o enunciado pretende exprimir o pensamento de seu locutor, aquém de qualquer jogo de linguagem. Não se trata, então, de uma argumentação, de uma resposta, de uma narração, mas de uma tese, de uma afirmação soberana;

c) na enunciação textualizante, há heterogeneidade enunciativa, por exemplo: diferentes figuras do enunciador, diferentes status polifônicos (citações), diferentes planos (primeiro plano e segundo plano), diferentes modos enunciativos (embreado e não embreado ${ }^{2}$ ). Na enunciação aforizante, não há mudança de planos enunciativos.

Além disso, enquanto a enunciação textualizante resiste à apropriação por uma memória (afinal, não é fácil memorizar um texto inteiro), a aforizante pretende ser uma fala sempre disponível, que estaria atualizando o que seria, de fato, "memorável". Na verdade, trata-se de um efeito de sentido desse tipo de enunciação, que se pretende como parte de um repetição que a sua própria enunciação autoriza. Desse modo, o sujeito enunciador, por meio da aforização, vai além da diversidade das interações imediatas dos gêneros textuais. Esse sujeito enunciador, o aforizador, assume um ethos específico, isto é, o ethos daquele que está no alto, do indivíduo autorizado que

2. Nos estudos linguísticos, um enunciado dotado de elementos que o ancoram na situação de enunciação é chamado de enunciado embreado. A ausência desses elementos, os embreantes (pronomes pessoais de primeira e segunda pessoas, pronomes possessivos de primeira e segunda pessoa, marcas de presente, etc.), caracteriza a enunciação não embreada, relativa a enunciados que se apresentam como independentes da situação de enunciação. A esse respeito, sugerimos Fiorin (1996). 
está em contato com uma fonte transcendente. Ele é aquele que enuncia algo que prescinde de negociação, como uma tese, uma verdade. Por isso, a aforização implica um sujeito enunciador que se situa como Sujeito de pleno direito. Assim, neste tipo de enunciação, o sujeito enunciador, segundo Maingueneau, coincide com o sujeito no sentido jurídico e moral: alguém que se coloca como responsável, afirma valores e princípios perante o mundo, dirigindo-se a uma comunidade que está além dos interlocutores empíricos que são seus destinatários.

Com todas essas propriedades, a enunciação aforizante não entra na lógica do texto e do gênero do discurso, mas ela é parte de um texto, já que não existe enunciado fora de texto, isto é, enunciado que não pertença a um certo gênero, que não siga uma rotina, um ritual, etc. Por isso, Maingueneau nos esclarece que a aforização é sempre convocada num texto que, por natureza, não é absoluto, embora ela pretenda ser uma fala absoluta, descontextualizada.

No caso do discurso de autoajuda para mulheres, há vários enunciados aforizados, conforme podemos notar especialmente em dois livros do corpus, a saber: "O que toda mulher inteligente deve saber" (Carter e Sokol, 2006) e "Homens gostam de mulheres que gostam de si mesmas” (Carter e Sokol, 2008). Nessas obras, há uma grande quantidade de aforizações, que se iniciam basicamente do mesmo modo, isto é, por meio da expressão "a mulher inteligente sabe que", que pode sofrer alguma pequena variação, por exemplo, "uma mulher inteligente sabe que", "as mulheres inteligentes sabem que". Nessas obras, as mulheres inteligentes são as que têm autoestima elevada, conforme podemos perceber nas passagens seguintes:

(03) A inteligência de que este livro trata está relacionada à capacidade de manter relacionamentos sadios e equilibrados. Mas só consegue alcançar essa sabedoria quem tem consciência de que, para ser feliz com qualquer pessoa, é preciso, antes de tudo, gostar de si mesmo, valorizar-se e respeitar seus verdadeiros desejos.

(Carter e Sokol, 2006: orelha da capa) 
(04) Vamos então começar a aprender com as mulheres que gostam de si mesmas. As que chamamos de "mulheres inteligentes".

(Carter e Sokol, 2008: 8)

Conforme as reflexões de Maingueneau (2010: 15) sobre a enunciação aforizante, as aforizações presentes no discurso de autoajuda, assim como ocorre com todas as aforizações, exigem um trabalho interpretativo, no qual dizendo $\mathrm{X}$, o locutor implica $\mathrm{Y}$, onde Y pode ser justamente um enunciado genérico de valor deôntico ${ }^{3}$. Ou seja, esses enunciados aforizados, inclusive os metafóricos, podem se reduzir a uma injunção, a uma interpretação imperativa, mesmo que os seus verbos estejam no presente do indicativo precedido de um sintagma nominal na terceira pessoa. Vejamos alguns exemplos:

(05) A mulher inteligente sabe o que fazer para que o primeiro jantar não se transforme na última ceia.

(Carter e Sokol, 2008: 39)

(06) As mulheres inteligentes sabem que... dramalhões são ótimos em peças de teatro, mas péssimos em um relacionamento.

(Carter e Sokol, 2006:120)

(07) A mulher inteligente sabe que... um homem gosta de uma mulher que não transforma todos os diálogos em monólogos sobre suas necessidades e sentimentos.

(Carter e Sokol, 2008: 157)

Parafraseando esses enunciados por uma injunção, teríamos, respectivamente:

(i) A mulher não deve ser precipitada.

(ii) A mulher não deve ser dramática.

(iii) A mulher não deve falar muito sobre as suas necessidades $e$ sentimentos.

3. A modalidade deôntica é a modalidade linguística que se refere ao eixo da conduta, ao qual se ligam os valores de permissão, obrigação e proibição. 
Como os enunciados aforizados podem ser parafraseados por enunciados deonticamente modalizados, fizemos um levantamento das paráfrases de vários dos enunciados aforizados encontrados nessas obras, o que nos levou a enunciados do tipo: "a mulher não deve ser insegura", "a mulher não deve ser neurótica”, "a mulher não deve ser excessiva”, "mulher não deve se revelar super interessada em casamento", "a mulher não deve choramingar", "a mulher não deve mexer na correspondência do homem", etc. Conforme essas paráfrases evidenciam, segundo o discurso da autoajuda, a mulher é insegura, neurótica, muito faladeira, muito desesperada, muito afobada, muito dependente, etc. Seja como for, a idéia que prevalece é a de que a mulher não tem controle emocional. Quer dizer, ela é retratada como alguém que não domina suas necessidades afetivas, sua carência, seu impulso sexual, seu apetite, nem mesmo seu desejo de falar. Tratase, então, de uma imagem de mulher que não condiz com o perfil da mulher contemporânea, que já assumiu o controle de sua vida.

A propósito, a respeito dessa falta de controle emocional, consideramos interessante destacar uma observação feita por Possenti (2007) num trabalho sobre textos de humor que tematizam a mulher. Conforme nota o autor, nos textos em que analisou, as mulheres têm uma reação desesperada diante de um problema de beleza, que é a celulite, como se se tratasse de um problema realmente muito grave. Embora essa forma de retratar a mulher possa ser considerada como efeito do modo caricatural como o discurso de humor costuma tratar os indivíduos a que se refere, parece-nos possível perceber ai também mais uma reprodução desse estereótipo de mulher sem controle emocional. No trabalho citado, Possenti questiona a relação que há entre o discurso de humor relativo a mulheres e as condições reais de existência das mulheres na sociedade atual. Segundo o autor, apesar de todas as mudanças pelas quais a vida da mulher passou, o discurso de humor continua tematizando tarefas consideradas típicas de "mulher" ou a permanência de situações em relação às quais o comportamento da mulher e do homem seria o mesmo de antes das mudanças sociais ocorridas nas últimas décadas. Ou seja, de modo geral, certos textos de humor indicam que a vida das mulheres não mudou muito, ou, 
indicam que, no mínimo, apesar das supostas mudanças, há ainda muitas contradições. Nos exemplos de que trata o autor ao longo de seu trabalho, podemos perceber que o campo humorístico e o publicitário funcionam fundados na manutenção ou na retomada de posições antigas, alimentando velhos estereótipos sobre as mulheres (tais como: a mãe zelosa, a responsável pelas tarefas domésticas, a consumista, a excessivamente preocupada com a beleza).

De acordo com Possenti, a presença de tais estereótipos nesses discursos pode ser tomada de duas formas: como indício de que a realidade social das mulheres não mudou tanto quanto se imagina ou de que há discursos, como os citados, cujo vínculo com a memória (discursiva, social) é mais forte do que o vínculo com a realidade social. Para o autor, corroboram a primeira hipótese alguns fatos relativos à vida atual das mulheres, tal como o de que os seus salários são mais baixos que os dos homens, o de que a sua progressão profissional é mais lenta que a dos homens, o de que continuam responsáveis pela criação dos filhos. Nesse caso, o cotidiano das mulheres continua como há décadas e o discurso do humor poderia ser lido então quase factualmente, como uma forma de dizer que ainda restam muitas formas antigas de vida social, ou de nos alertar para o fato de que as coisas mudaram bem menos do que pensamos.

Por outro lado, segundo o autor, a segunda hipótese ganha reforço quando nos lembramos de que a publicidade promete o impossível e o humor se alimenta de estereótipos. Sendo assim, seria até legítimo imaginar que a exploração desses estereótipos antigos em certos discursos esteja ligada justamente às mudanças sociais, como uma forma de rememorar uma história passada; nesse caso, o discurso de humor estaria apenas representando fatos que fazem parte da memória (talvez, até, como uma forma de resistência).

Esses velhos estereótipos sobre a mulher também foram identificados em outros trabalhos que analisaram os mesmos tipos de discurso tratados por Possenti (2007), isto é, o discurso de humor e o publicitário.

Sobre o discurso publicitário, aludimos ao trabalho de Mussalim (2007) sobre a constituição de identidades femininas em propagandas 
publicadas em revistas destinadas à mulher, entre os anos de 1980 e 2000 no Brasil. Conforme afirma a autora, a partir da segunda metade do séc. XX, a constituição da identidade feminina no discurso publicitário tem considerado a diversidade e o pluralismo dos papéis da mulher na nossa sociedade. Considerando os exemplos apresentados nesse trabalho, podemos notar que, embora a publicidade atual explore a imagem da mulher como a profissional bem sucedida, também estão presentes nesse discurso os velhos papéis associados à mulher (a mulher como esposa, como mãe zelosa, como dona de casa, como sedutora e preocupada com a beleza).

Fonseca-Silva (2007), por sua vez, analisa textos humorísticos nos quais estão presentes diversos temas associados às mulheres, como beleza, família, filhos, angústias da mulher moderna. Basicamente, nos textos analisados, a mulher é a que luta constantemente e sem descanso procurando ter sucesso nas suas diferentes funções (como esposa, como mãe, como amante, como dona de casa, como profissional, com o seu corpo), o que acaba a levando a um estado de "euforia e depressão". Ou seja, nesses textos podemos perceber que os papéis antigos da mulher fazem parte da diversidade e do pluralismo dos papéis associados à mulher na sociedade atual, e o foco dado parece recair justamente no modo como isso tudo afeta negativamente as mulheres (daí as angústias, os desesperos e alterações que marcam o comportamento das mulheres retratadas nos textos analisados).

Considerando, então, os resultados desses três trabalhos (Possenti, Mussalim e Fonseca-Silva) e especialmente os questionamentos levantados por Possenti (2007), podemos dizer, de um ponto de vista mais amplo que, nos campos citados (o campo do humor e o publicitário), a diversidade dos papéis femininos é reconhecida, mas a ela ainda se associam velhos estereótipos, segundo os quais as mulheres continuam com os mesmos interesses e preocupações, ou seja, filhos, casamento e beleza, para citar os mais comuns. Assim, esses resultados evidenciam como esses discursos colaboram com a manutenção e com a propagação desses velhos estereótipos femininos. O mesmo pode ser dito a respeito do discurso de autoajuda, especialmente se 
considerarmos uma obra como Sansone (2008), cujo subtítulo é: "mãe de 10 filhos ensina como cuidar da família, manter a boa forma e ser feliz no casamento". Por esse subtítulo notamos que o discurso de autoajuda também associa às mulheres os mesmos temas de sempre: cuidados com a família (maridos e filhos) e com a beleza. Alguns dos títulos das seções do livro também se referem à mesma temática. Por exemplo, sobre o tema da beleza temos: "Inclua a malhação na rotina diária" (Sansone, 2008: 64), "Mantenha-se em dia com o básico da beleza" (Sansone, 2008: 71); sobre o tema do casamento, há seções como: "Demonstre admiração por seu marido" (Sansone, 2008: 95), "Resgate a sensualidade dos tempos de namoro" (Sansone, 2008: 122); por fim, vejamos algumas seções sobre o tema da família: "Reúna a família" (Sansone, 2008: 161), "Crie um lar seguro" (Sansone, 2008: 162), "Faça das refeições um momento de alegria" (Sansone, 2008: 157), "Ensine as crianças a organizar a própria vida" (Sansone, 2008: 171).

Para compreendermos melhor o funcionamento dos estereótipos de mulher no discurso de autoajuda, retomamos algumas das ponderações que Amossy e Pierrot (2001) reúnem sobre os estereótipos, dialogando com diversas perspectivas: ciências sociais, literatura, retórica, análise do discurso. Desse diálogo, gostaríamos de recuperar alguns aspectos relativos aos trabalhos da Psicologia Social, no âmbito das Ciências Sociais, segundo a qual o estereótipo pode ser entendido como uma crença, uma opinião, uma representação relativa dos membros de um certo grupo social. Diferencia-se, assim, do preconceito, que diz respeito à atitude negativa que se adota com relação ao grupo em questão.

\section{Considerações finais}

Os estereótipos são representações cristalizadas sobre um grupo social, são esquemas culturais preexistentes. De modo geral, trata-se de imagens fictícias que expressam um imaginário social. Em alguns trabalhos da área, o caráter negativo dos estereótipos 
se liga aos processos de categorização e generalização do real, que o simplificam, produzindo uma visão esquemática e deformada que favorece os preconceitos. Sobre a relação dos estereótipos com o real, as autoras nos lembram que os estereótipos podem propagarse sem nenhuma base objetiva, isto é, sem nenhum núcleo ou fundo de verdade. Por isso, podem ser considerados como um aprendizado social resistente, que não se invalida mesmo com a observação direta e que pode moldar a nossa percepção. Lippman (1946, apud Amossy e Pierrot, 2001), pioneiro nesse tipo de investigação, considera que os estereótipos mediatizam nossa relação com o real, pois é através deles que filtramos a realidade que nos cerca. Os estereótipos são, assim, imagens indispensáveis para a vida em sociedade, pois nos permitem compreender o real, categorizá-lo e agir sobre ele. Daí a tese, defendida pelo autor, segundo a qual o que vemos é o que nossa cultura definiu previamente.

Apesar disso, os estereótipos não são necessariamente totalmente arbitrários. Eles podem até ter uma base factual observável, o que não elimina os problemas, pois, ao estereotipar membros de um grupo social, os traços de seu status social e de seus papéis são representados como se fossem uma essência imutável. No caso da mulher, por exemplo, mais do que reflexos da essência feminina, os estereótipos refletem os papéis sociais da mulher, o que se espera que ela faça ou que continue fazendo. Nesse sentido, o estereótipo é efeito de uma distribuição social de papéis, o que supera a questão da verdade e põe no centro das reflexões o uso que se faz dos estereótipos. Não se trata, portanto, de comprovar ou não a exatidão dos esquemas coletivos cristalizados, mas de verificar como os estereótipos afetam a vida social e a interação entre os grupos.

Desse ponto de vista, podemos dizer que o discurso de autoajuda, baseando-se numa imagem negativa de mulher ou mesmo associando-a aos temas costumeiros, está, de uma certa forma, colaborando para a manutenção dos velhos estereótipos sobre a mulher, o que é, sem dúvida, muito favorável a esse discurso, já que ele só se justifica se a mulher realmente se identificar com eles. É por isso, inclusive, que a Psicologia Social afirma que os estereótipos levam com frequência a 
formação de círculos viciosos, nos quais a adesão ao estereótipo leva a sua reprodução. A esse respeito, Amossy e Pierrot (2001) afirmam:

Seguindo a mesma lógica do círculo vicioso, o da profecia que provoca a sua própria realização, os membros dos grupos estigmatizados se adéquam à imagem desvalorizada que thes devolve um meio hostil. Interiorizando o estereótipo discriminatório, eles são levados a ativá-lo no seu próprio comportamento (AMOSSY e PIERROT, 2001, p. 43; tradução nossa).

Sendo assim, evidenciamos a contradição própria ao discurso de autoajuda que propõe à mulher um padrão de comportamento mais condizente com a sua suposta emancipação ao mesmo tempo em que colabora com a reprodução dos estereótipos femininos que a desvalorizam socialmente.

Recebido em: abril de 2012 Aprovado em: outubro de 2012 anna@ibilce.unesp.br

\section{Referências bibliográficas}

ABRAÃO, S. Abaixo a mulher capacho!. Barueri: Manole, 2009.

AMOSSY, R.; PIERROT, A. H. Estereotipos y clichês. Buenos Aires: Editorial Universitária de Buenos Aires, 2001.

ARGOV, S. Por que os homens amam as mulheres poderosas: um guia para vocês deixar de ser boazinha e ser tornar irresistível. Rio de Janeiro: Sextante, 2009.

. Por que os homens se casam com as manipuladoras. 9a. ed. Rio de Janeiro: BestSeller, 2010.

CARTER, S; SOKOL, J. O que toda mulher inteligente deve saber: como lidar com os homens com sabedoria e conseguir o amor que você merece. Rio de Janeiro: Sextante, 2006.

. Homens gostam de mulheres que gostam de si mesmas: e outros segredos que as mulheres inteligentes sabem. Rio de Janeiro: Sextante, 2008. 
FIORI, J. L. As astúcias da enunciação: as categorias de pessoa, espaço e tempo. São Paulo: Ática, 1996.

FONSECA-SILVA, M. C. Humor e práticas de subjetivação em Maitena. Estudos da Língua (gem), v.5, n 1: 95-108, 2007.

FRANKEL, L. P. Mulheres ousadas chegam mais longe: como evitar os 101 erros que atrapalham sua carreira. 8a . ed. São Paulo: Editora Gente, 2005.

. Mulheres boazinhas não enriquecem. São Paulo: Editora Gente, 2006.

MAINGUENEAU, D. Doze conceitos em análise do discurso. In: Souza-eSilva, M. C. P. e Possenti, S. (orgs.). São Paulo: Parábola, 2010.

MUSSALIM, F. A constituição de identidades femininas no discurso publicitário. Estudos da Lingua (gem), v.5, no 1: 109-124, 2007.

POSSENTI, S. Discurso humorístico e representações do feminino. Estudos da Lingua (gem), v.5, n 1: 63-94, 2007.

SANSONE, K. Mulher em primeiro lugar: mãe de família ensina como cuidar da família, manter a boa forma e ser feliz no casamento. Rio de Janeiro: Sextante, 2008. 